\title{
How to improve the college students learning ability
}

\author{
Yu Yingying ${ }^{1, a}$, He Peng ${ }^{2, b}$
}

${ }^{1}$ No. 7855 Renmin street Airforce aviation university Changchun Jilin province China

${ }^{2}$ No. 7855 Renmin street Airforce aviation university Changchun Jilin province China

aemail:285548542@qq.com, bemail:38970883@qq.com

Keywords: improve, learning ability.

Abstract.This article through to the changchun city college students learning motivation, learning attitude, learning methods and teaching methods of questionnaire survey, it seriously analyzed the relevant factors that affect college students' learning ability, finally proposes countermeasures and Suggestions in view of the problem.

\section{Introduction}

Under the Internet+ background, the rapid expansion of knowledge, like cell aging, death, update every day. National construction need is to be able to keep up with the knowledge update. That is to say, talent is timeliness, to ensure that the talent is not to be eliminated, learned knowledge is not aging, you must be learning force as the backing, such talent to keep up with the pace of the social advancement. Throughout the contemporary colleges and universities, in the traditional teaching management mode and position under the pressure of employment, the young college students more pursuit of employment as a result, while ignoring the molding process of their own learning ability and training. Educators changing ideas, this needs us to cultivate students learning ability as the center, construct the new education management mechanism.

\section{College students' learning situation analysis}

To understand the characteristics of the college students' learning, this article to jilin university, northeast normal university, changchun university of science and technology, changchun university of technology, changchun university of finance and economics, jilin normal university, changchun normal university college students' questionnaires of seven universities such as random survey.Recycling effective questionnaire 1573, in view of college students' learning motivation, learning attitude, learning methods, learning environment and the approval of teachers' teaching methods and results are as follows:

a. Learning motivation 


\section{Learning motivation}

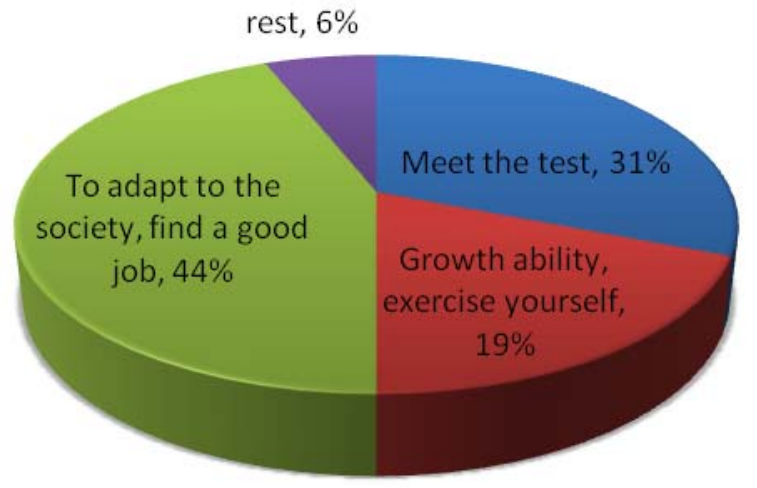

Meet the test

Growth ability, exercise yourself

$\square$ To adapt to the society, find a good job

$\square$ rest

b. Learning attitude

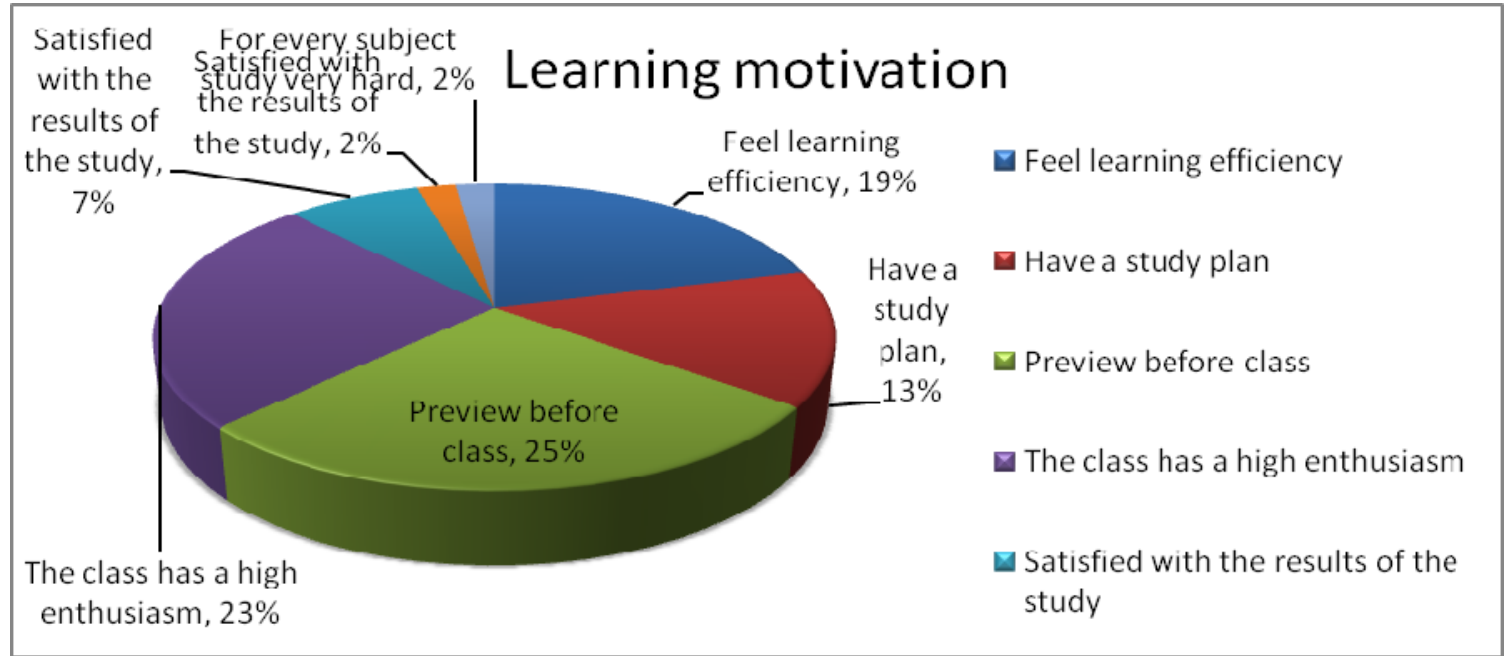

c. Learning methods

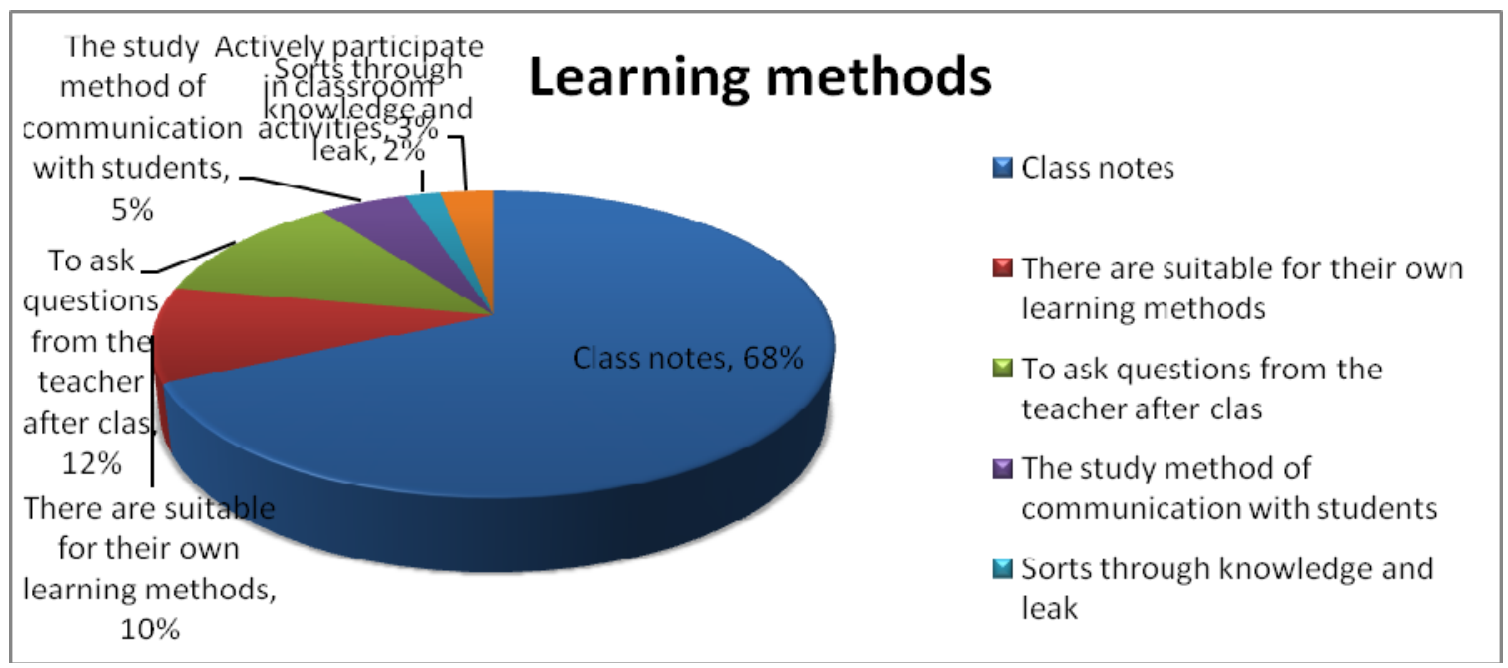

d. The influence of teacher's teaching method 


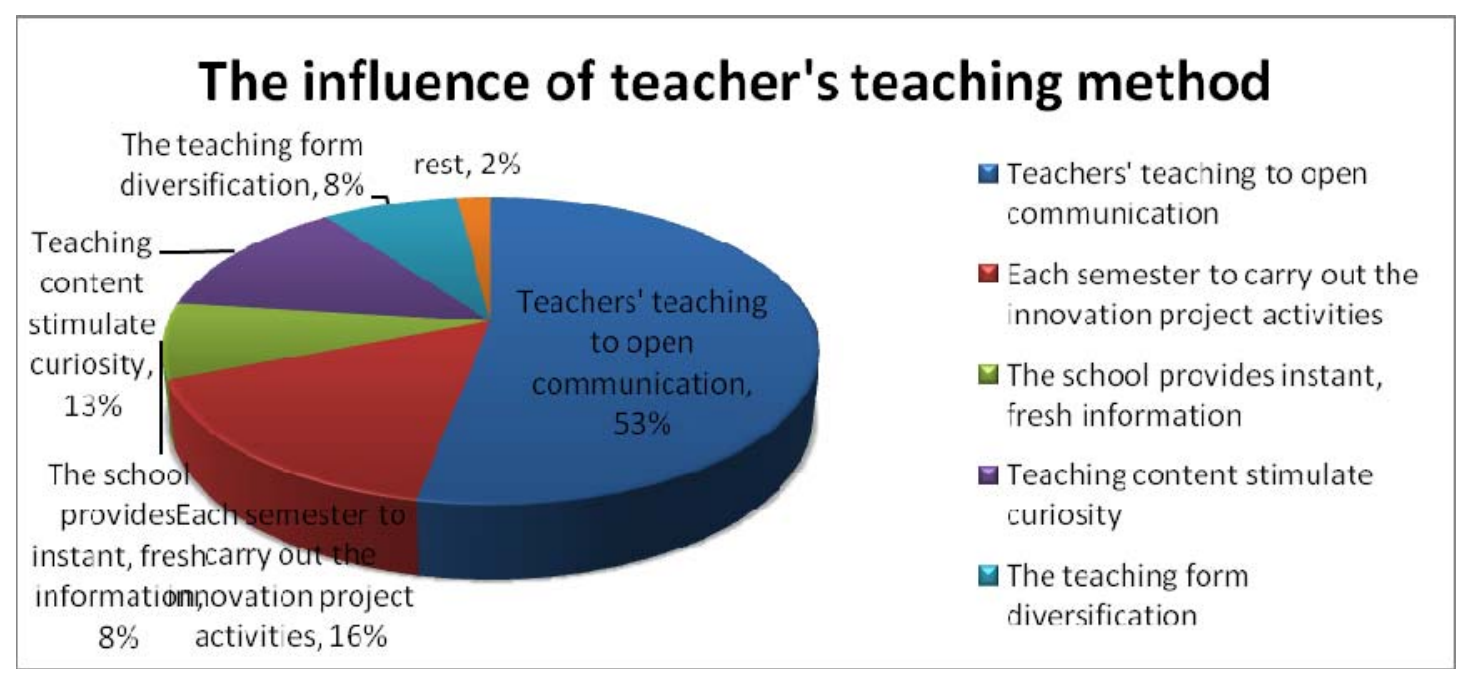

In the information age, college students improve learning ability, is more important than attaches great importance to the academic achievement and knowledge. However, from the results of the survey, in gradually expand the scale of colleges and universities in our country, the number of students have a lack of learning force. Students study is examination of the heart, it is work, rather than innovation and interest. All of this, it's all in killing countless individual creativity, serious said is in killing the upgrade and vitality of the Chinese nation. Some students learning ability is only a period of weak state, while others continue through the university level. Learning ability is insufficient, to improve the quality of our higher education brings many problems, get rid of this predicament is the theme of contemporary education. Way to cultivate the learning ability of college students' study, to explore college students learning the "way", is particularly important and urgent.

\section{The factors influencing college students' learning ability}

One level of the ability of competition is not the same as the academic record, degree of high and low, but in his learning ability .No matter in what position, must be able to keep learning, according to the environmental changes constantly change myself, take the initiative to adapt to the society. Visible, true learning ability is not confined to the learning ability of knowledge, but also through the practice, experience and reflection, the new thinking, new ability.

Chinese scholars Huang Jian points out, "refers to the individual learning ability to absorb knowledge, using knowledge ultimately change the ability to work and life, learning ability is not only the learning ability of the question, also involves emotional things, factors, that is, an individual's attitude to learning, personal learning ability but also is closely related to the individual's physiological condition."Visible, factors affecting students' learning ability is not single, but is multifaceted. The first is individual difference. Due to family education, growing environment and the influence of different teacher education teaching methods etc, and the causes of gender, mental physiological maturity, each college students shows the overall style is different. Secondly learning environment. The learning environment refers to the hardware condition of campus construction, not only let students hear campus culture and positive learning atmosphere of endeavour.

But, regardless of gender, physical ability, how big is the difference of learning environment, the basic principle of learning, motivation, effective teaching for every learner. Learning ability includes three factors: learning needs, will and ability to learn. When there's a study demand also creates a goal, it is the premise of learning; Had a target will inspire learning will, and will cooperate with the corresponding learning ability can achieve very good effect. Thus, to improve 
the learning ability of college students, to stimulate their learning needs, will guide their learning, cultivate their ability to learn.

\section{College students' learning ability cultivation measures}

In knowledge economy era of rapid growth, in order to make students form the multiple Angle of view of knowledge itself and the world, giving them the ability of knowledge, skills, thinking and life, enable them to form the concept of lifelong learning, and life to be able to adapt to environmental changes, to help the students have the benefit their lifelong learning ability is of great significance, is the so-called "to teach fishing is better than to fish".

a. To improve college students' autonomous learning ability

One is the learning motivation. To make every college students can develop conscious, active learning attitude, have to trigger their learning motivation. Never too old to learn, to make the students understand that learning is not just for the purpose of acquiring the knowledge in their place, but learning method, learning more far-reaching significance is that can improve the learning ability, better adapt to the rapidly changing society and life in the future.

The second is to encourage individual learning. We are now more emphasis on education is professional knowledge, the gates of this professional course that they require students to learn, it will cause students' learning interest is low, the status of the passive learning. Although we have different degrees of in the promotion of autonomous learning, but much homework as traction. In today's Internet resources with the environment, we should change the ideas, due to the student learning autonomy, truly become "knowledge" to "explore knowledge". Encourage students based on personal interest and need to solve problem for autonomous learning. Through a variety of effective way to learn, build them to meet their learning of personalized knowledge structure. In this way can let students really willing to learn, active learning.

b. Adjust the teaching mode and teaching method

One is to change teaching methods. University teachers more in class is to have a class, come on, go up. Teaching method is unitary, boring, it is difficult to capture the interest of students. Want to learn the students follow the teacher teaching content to take notes, students are not interested in brush may be put to sleep or mobile phone. To improve the learning ability of students, first of all, is about to change the old teaching methods, design a relaxed learning atmosphere and the class content, can be the theme of the professor will be mystification, with "problem" for the center, knowledge through; Or conveyed to his personal experience of exert a subtle influence on students, causes the student's year of curiosity and interest in this topic, further thinking, let the students themselves to find the methods to solve the problem.

Second is to adjust teaching mode. The main for the teacher's role of "knowledge to doubt", in the classroom teaching of the course content. In micro lesson, lesson for all kinds of information resources of coming today, to improve the learning ability of students, really inspire their creativity, is about to change the existing standardized teaching model, will discuss the classroom into a room, the teacher taught by past into a leader of the discussion. The content of the textbook by the students to preview before class or self-study, class by the teacher guide the discussion and opinion interaction, such study can not only meet the students' personality, and encourage the development of the students innovative ability.

Third is to build the informationization teaching resources. Now the domestic and foreign high-quality information-based education teaching resources are very abundant, research and development of various education teaching platform for the students learning provide a large number of mobile resources. This makes learning is no longer just limited to the classroom, the students can easily implement learning in every corner of life. Therefore, colleges and universities 
to build advanced, efficient, flexible and practical digital education teaching infrastructure, integration of resources, expanding the area of information technology teaching, provide a good network learning environment for students.

\section{Summary}

The social organization published the book "learn to survive", there is such a word "the future of illiteracy is no longer illiterate people, but people who don't have to learn how to study."The process of learning process is not to copy books, more is not a formula for calculating process, but from the study grope for suitable for their own learning methods, to learn the skills, avoiding the phenomenon of learned you forget. Therefore, improve the learning ability of college students is the current higher education faces is the important subject to be solved.

\section{References}

[1] Zhuang Huilian, The study on the Survey and Promoting Strategies of college Students' Web L earning Power,(2012)

[2] Xiao Liangsha, The cultivating ways of students' learning ability. (2011)

[3] Ji Guanghua,The constructing of Information Technology to lifelong learning capacity.(2006)

[4]Cao Rong,Liu Yong, College students' learning ability and its promotion strategy research.(2015)

[5]Wei Ping, The theory of college students' learning ability.(2014) 